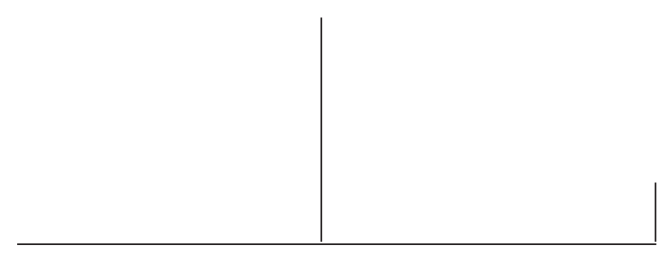

Rev. Latinoam. Psicopat. Fund., X, 2, 231-254

\title{
Para pensar o afeto
}

\author{
Aluisio Pereira de Menezes
}

Apresentação de um conjunto de formulações relativas ao "afeto" anteriores ao surgimento da psicanálise. Dificuldade da psicanálise em construir uma concepção propriamente psicanalítica. Contribuição da fenomenologia de Husserl para o estudo do afeto. Atualidade das concepções do afeto marcadas pelas neurociências. As maneiras principais de ver o problema da conceituação do afeto no pensamento psicanalítico.

Palavras-chave: Afeto, psicopatologia, fenomenologia, concepção psicanalítica do afeto 


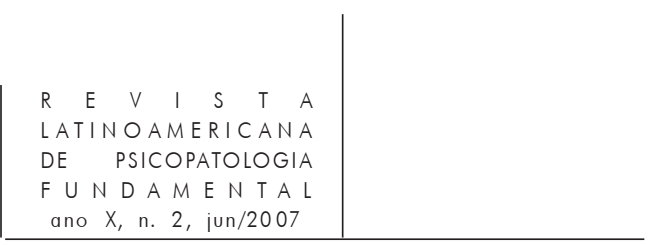

A cada momento, o mundo poderia ser transformado em todas as direções,
ou pelo menos em qualquer uma; ele tem isso, por assim dizer, no sangue.
Por isso seria original tentar comportar-se não como um homem definido
no qual não há mais, seria possível dizer, do que um ou dois botões
(é o que chamam de evolução), mas, desde o início,
como um homem nascido para a mudança num mundo criado para mudar,
isto é, mais ou menos como uma gota numa nuvem.

Robert Musil

O universal é o local menos os muros.

Miguel Torga

O afeto existe como noção que importa considerar. Existem fenômenos que são considerados e nomeados como sendo de ordem afetiva. É facílimo constatar a variação semântica do termo (como substantivo no singular ou no plural, na referência ao verbo e na adjetivação) por todos aqueles que dele fazem um uso, digamos, técnico. A partir de certa época na cultura ocidental, começa a ser empregada também a palavra "afetividade". Tem-se aí um uso mais abstrato do que veio sendo nomeado como afeto e que parece supor uma distância e uma dobra, colocando o afeto como categoria do pensar e das construções psicopatológicas.

Além disso, pode ser considerado um termo que ressurge nos desdobramentos da construção da noção de sujeito moderno, a partir de Descartes. De modo mais particular, fica sendo comum associar a fenomenologia ao despertar da consciência que conduz ao termo "afetividade". Sabe-se, contudo, da inflexão kantiana como decisiva nesse caminho. Assim, possivelmente toda essa ênfase decorra de uma reflexão sobre o que o século XVIII já havia podido colocar, de modo quase pletórico, numa diversidade de autores e de seus lugares (religião, filosofia, medicina, ficção, psicofisiologia, psicologia), tematizando de múltiplas maneiras o ser afetado por algo que domina, e que seria da ordem do incontornável, determinando um modo de vida e um destino. 


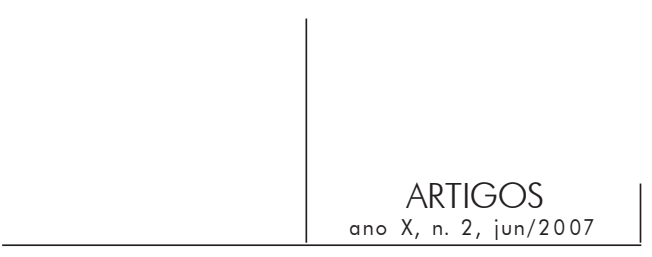

A figura do ser vítima passiva mostra, metaforicamente, a posição de quem se vê na afetação do outro indominável. Essa figura encontra no uso coletivo do mito sua primeira conformação. Ela se situa no plano religioso, muito antes de designar algo relativo à interioridade de um indivíduo. Entretanto, o sentido do afeto no léxico das instituições indo-européias está referido à idéia de pertença e de filiação, e é dentro dessa circunscrição que as palavras designam o afetivo, a idéia de sentimento (Benveniste, 1969). Portanto, além de comportar tais significações, os gregos as trabalham no seu universo mito-poético. É nesse contexto que surge a figura da vítima passiva sem qualquer conotação propriamente subjetiva e individual. Só depois de Homero, com a poesia lírica, com a tragédia e com a filosofia é que se começa um distanciamento do plano religioso estrito (Vernant, 1965; Dodds, 1951; Vernant e Vidal-Naquet, 1981) em direção aos móveis do subjetivo e suas razões.

A importância da tragédia grega, já em outro regime religioso, econômico e político, é a de que nela se discutia, se pensava, se mexia a certeza de uma estética de base afetiva para a qual valeria ser aterrorizado, possuído, dominado, vítima passiva diante de forças maiores que paralisam e ultrapassam a consciência.

Coloca-se uma vibração sensorial que arrebata, dobra, torna o atingido outro antes dela. Se os eflúvios de Pã dominam a cena de formação da identidade e do gênio gregos, do momento dos pré-socráticos a Aristóteles, o que se tem quanto ao afetivo será considerado à luz da individuação num processo cada vez menos marcado pelo mítico-religioso. A razão se autoconscientizando, através do domínio discursivo, ainda assim esbarra com seu outro que a quebra e mostra o temor dominador, paralisante por estar-se diante de algo maior. Como lidar com isso? Como agir se existe um limite à determinação da vontade e à do comando? Esse é certamente um pano de fundo para se apreender o sentido grego da passividade que alimenta o que, atravessando estoicismos, cristianismos e modernidade, virá, depois de séculos, a ser conceituado através do termo afetividade.

Esses tópicos indicam, aproximadamente, o longo caminho das significações relativas à problemática do afeto e aos temas necessariamente associados que antecederam àquelas formuladas pela psicopatologia psiquiátrica (compreensiva e psicofarmacológica) e pela psicopatologia psicanalítica inicial. Portanto, dos gregos ao século XVIII, a Kant, à neurofisiologia do século XIX, tais significações marcam as construções psicopatológicas. Como o nosso interesse aqui é situar, com alguma clareza, o que é concebido efetivamente enquanto afeto em psicanálise, acredito ser verificável que a dimensão remanescente dessa semântica quase impediu e continuou impedindo uma autonomia conceitual do afeto que seja particularmente pensada em função da hipótese do inconsciente e da "mitologia pulsional", para falar de maneira sintética. 


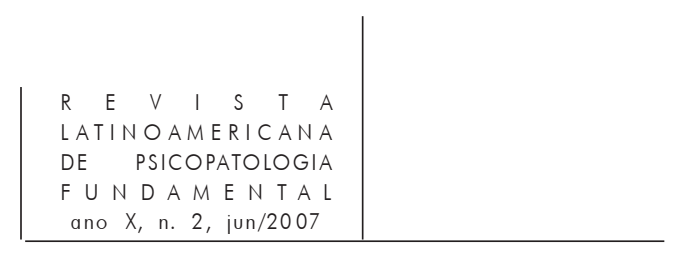

Abordar o afeto significa, nas formas de pensar dos psicanalistas, o desafio diante de uma dificuldade. Tem sido assim há muito tempo, desde o início, mesmo com Freud.

De todo modo, há assim os que levam em conta a estrita necessidade de rigor no empenho em precisar-se o que estamos dizendo quando usamos um conceito num campo específico do trabalho coletivo de formação e de atuação - seja no modo liberal, seja no institucional - de estudiosos, práticos e gestores de uma mesma área de conhecimento e de ação. E há também aqueles que tomam a noção como secundária, subordinada ou até inútil, dentro de idênticas condições. Pouco importa, tanto confiando no rigor, quanto ficando a ele indiferente, ou desprezando-o, onde quer que esteja em causa o "afeto" se evidencia, sempre, a oscilação semântica e mostra-se bem que, mesmo com uma disposição negativa, não se consegue ficar livre da flutuação. Aquele que tem o conceito como que de pouco ou de nenhum valor e aquele que investe em concebê-lo efetivamente, ambos se contradizem no uso e na teoria, presos em automatismos conceituais que acabam tornando a continuidade do discurso um contra-senso, senão apenas uma confusão se formos de fato muito exigentes.

Percebe-se, com toda evidência, que as maneiras como o afeto (toda esta área semântica envolvendo a "afetividade") é referido e balizado nunca são unívocas. Alguns saberes partilham a dificuldade. Atendo-se aos saberes que trabalham com algo que poderíamos chamar de valor psíquico e existencial (mesmo suspendendo-se a dimensão histórica implicada neste valor) seria possível marcar que ele não poderia ser reduzido ao que as perspectivas neuronais localizacionistas e eletrobioquímicas consideram como o poder de explicação e de tratamento no enfretamento das situações problemáticas ou psicopatológicas. A maneira como a "afetividade" será concebida justificará esta ou aquela ação de tratamento e certamente terá efeitos a médio e longo prazo na conformação da cultura (Canguilhem, 1980).

Duvido que se possa fugir disso, mesmo que não saibamos ao certo o que queremos dizer quando recorremos a algo que precisaria ser levado em conta como sendo da ordem do afeto. O importante é perceber a pouca consistência do que concebemos como sendo o afeto e os fenômenos do afeto. Essa dificuldade também se dá na psicanálise, a qual, supostamente, seria mais sensível ao que é o objeto do questionamento. O que significa, a partir da psicanálise, dizer que "fulano é afetivo" e que "sicrano não o é"? Apesar de alguns esforços significativos, os argumentos de autoridade não conseguem dirimir a maneira precária de conceber, face ao desafio posto por situações psicopatológicas, seus enigmas, suas dificuldades, e suas conseqüências no modo de ser individual ou coletivo. E, apesar disso, trabalhamos mentalmente - mesmo quando a rejeitamos 


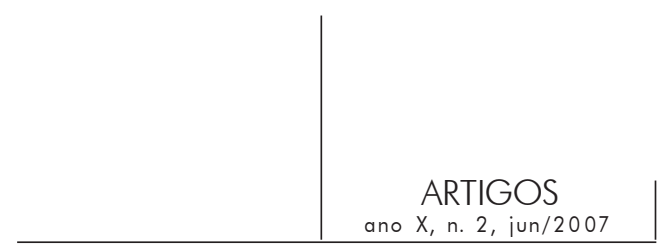

- com esta referência categorial, ou então a tematizamos explicitamente conforme nossas obediências institucionais, morais e teóricas.

Diante disso, seria bom, à guisa de exemplo de controle, que meditássemos sobre o que deveremos entender por afeto no discurso de um homem influente num determinado setor da cultura do capitalismo, lá nos anos 1980. Embora o objetivo não seja aqui levar a cabo a análise do que estaria em jogo nessa forma de pensar o afeto, gostaria de citar a passagem para que o leitor medite sobre o que ele pensa sobre o afeto ao dizer o que assinala o emprego da palavra afeto. No contexto que dá sentido ao que aquelas palavras significam, é fácil reconhecer que a noção de afeto é ali empregada tornando porosos o tecnológico, o capitalismo, o afeto por uma mediação e o afeto propriamente existencial, já que se trata da experiência de vida que alimenta o imaginário dos consumidores.

Fala Boni, Superintendente de Produção, Programação, Engenharia e Jornalismo da TV Globo. O segredo da televisão é comum a outras que produzem para o grande consumo. É o posicionamento correto diante de seu mercado e a entrega de um produto adequado, capaz de conquistar a confiança dos consumidores. Isto é, com uma boa estratégia de marketing forma-se o hábito, que é a conseqüência e não causa.

Para habituá-lo a ver nosso canal, precisamos colocar no ar um produto que você e o mercado estejam dispostos a consumir. E você e o mercado têm que confiar que, assim que aquele produto acabar, vai ser substituído por outro que mereça igual confiança. Na relação do hábito passa a existir também a afetividade. $\mathrm{O}$ espectador fica habituado a ver televisão porque passa a ter afeto por ela. E como se conquista esse afeto? Prometendo as coisas e cumprindo... O segredo da televisão está em criar o hábito. (Kehl, 1986, p. 186; grifo meu)

A leitura da passagem deixa claro que algumas abordagens são possíveis. O texto, no entanto, está aqui mencionado porque recorre aos termos "afetividade", "ter afeto por" e "afeto" (um afeto determinado, "esse afeto"). Além disso, o uso dos três termos pressupõe uma articulação de caráter conceitual. No contexto que delimitará sua significação, o que está em jogo é a capacidade de conquistar a fím de criar um vínculo "afetivo" continuado. O que interessa de saída é a possibilidade de perceber que a maneira como a coisa é dita revela que a noção de afeto foi evocada para mostrar o profundo vínculo que o telespectador mantém com a televisão. O que serão os afetos para que possam ser conquistados e explorados na dependência do hábito? Não cabe aqui desenvolver o conteúdo do que é dito enquanto problema, enquanto questão, mas sim observar que uma certa concepção do afeto está acoplada a um interesse e a um processo. Afeto e consumo ficam articulados.

Trata-se de uma concepção instrumental do afeto dentro da qual se explica a adesão a produtos a serem consumidos por meio da experiência de natureza 


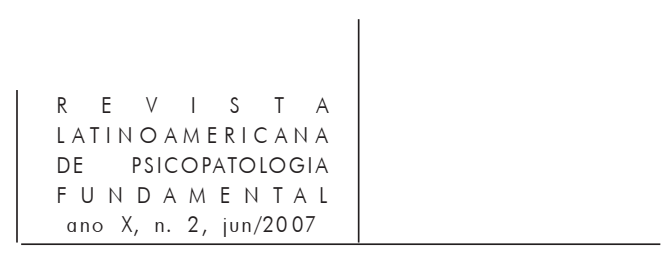

afetiva que vai sedimentando o hábito. É uma concepção que envolve a manipulação do afeto que comparece na adesão e também sua quantificação, uma vez que a busca de "qualidade" está determinada pelos índices de aceitação e adesão. Abrir a caixa preta desse processo permitiria discutir o que faz com que o ser afetado pelos produtos da televisão desenvolva uma afetividade por eles e estabeleça um vínculo duradouro.

Esse desvio, em relação ao que interessa aqui, pretende chamar atenção para o fato de que, quando lidamos com a noção de afeto, estamos lidando com uma semântica carregada, difícil de controlar, escorregadia. A tradição psiquiátrica, a sexologia, as psicologias, a psicanálise, seus múltiplos desdobramentos e cruzamentos, a psicofarmacologia e as neurociências não fugiriam de tal dificuldade, nem tampouco o cinema, e mesmo o romance. A leitura de textos relativos a esses saberes revela que todos eles estão marcados pela longa metafísica ocidental e também por autores e artistas que pesam a partir de meados do século XVII e ao longo de todo o XVIII, como vem sendo assinalado para se ter uma percepção histórica do problema. Se fosse possível apresentar o aspecto geral dessa inflexão que incide na semântica da noção de afeto, ${ }^{1}$ numa procedência filosófica desde os gregos, poderíamos então resumi-la assim: "passividade que escapa ao domínio da razão" (Richir, 2000).

Contudo, não existe um sentido único nessa "passividade". Ao contrário, por motivos diversos, é perceptível que se pode considerá-la tanto numa vertente interna, quanto numa perspectiva externa. Num caso, tem-se a deriva de toda uma construção conceptiva que levaria a tomar o momento apassivador como uma espécie de matriz originária da subjetividade, mas com a condição de não se pensar que se possa equalizar a noção de subjetividade, por exemplo, no contexto mítico grego, no aristotélico, no agostiniano, no de Montaigne, ou ainda no de Rousseau ou mesmo no das sutilezas do idealismo alemão. Noutro, a ênfase se centraria em pensar o fora como causa do que se coloca num momento de modificação instauradora, e também aí as construções são relativas à cultura que as vê nascer. Ao longo da cultura que foi constituindo a identidade ocidental cristã até a modernidade e suas crises, é possível situar a diversidade de conjunção dos termos razão, afeto, paixão e sujeito no plano dos discursos filosóficos, literários, teológicos e poéticos, antes ainda dos saberes construídos dentro de uma "vontade de fazer ciência".

1. Cf. O verbete Afficere: "afetar, tratar bem ou mal, fazer impressão no ânimo ou corpo, dispor, mover, comover; causar impressão agradável; gratificar, brindar, dotar, dar; causar impressão desagradável; atacar, ferir, aplicar castigo, condenar, oprimir”, em Saraiva, F. R. dos Santos. Novíssimo Dicionário Latino-Português; e também o verbete Adficere: "prover de; colocar em tal ou qual estado, afetar, dispor; enfraquecer, afetar", em Gaffiot, F. Dictionnaire Latin Français. 


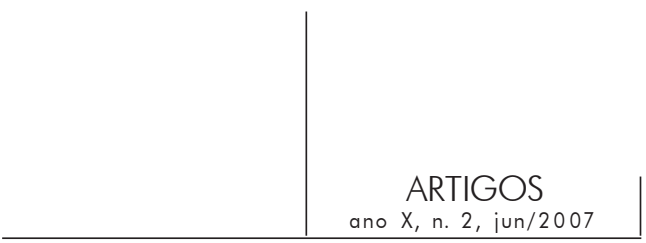

O objetivo dessas colocações é, pois, o de lembrar a anterioridade, o entrelaçamento conceptivo envolvido na semântica do pathos grego e na da "passio" romana e seus usos a partir de uma consciência ampliada e transmitida, através de épocas históricas certamente bem diferentes, mas articuladas pelo conhecimento de uma indagação sobre o sentido do ser subjetivo na vida humana na trajetória reflexiva do Ocidente. Há uma marca filosófica profunda, mesmo quando o que está em jogo tenha provindo do espaço mítico e religioso. De qualquer modo, por mais que, em cada construção histórica, se tenha uma determinação específica que impeça leituras unificantes e generalizantes, o fato é - e é este o ponto - que as construções psiquiátricas e, a seguir, as psicanalíticas, dependeram de toda essa tradição. Qualquer pessoa que se ponha a acompanhar a literatura psiquiátrica e a psicanalítica, poderá com facilidade verificar e constatar isso. Mesmo depois de estabelecida uma tradição psiquiátrica, a inflexão, aliás, extremamente rica, da fenomenologia marcará, de forma profunda, o discurso psiquiátrico, antes que a diretriz bioquímica, para falar sinteticamente, silencie bastante a tensão sutil que a clínica psiquiátrica pôde desenvolver em função da fenomenologia e da própria psicanálise.

No entanto, a deriva "materialista" provém de outra tradição, ela também grega em sua origem. Na segunda metade do século XX, ela foi, aos poucos, silenciando a contribuição fenomenológica, e também a contribuição psicanalítica. A concepção humoral da antigüidade certamente foi sendo retrabalhada, no espírito da ciência moderna, pela biologia molecular, portanto depois da fisiologia e da neurofisiologia do século XIX, da teoria da evolução, da anátomo-patologia, do tratamento científico das epidemias. Com a psicofarmacologia, com a epidemiologia, irá adquirir-se uma eficiência através de próteses medicamentosas capazes de modificar e estabilizar estados psicopatológicos: "paixões" e "afetos" são então biologicamente concebidos e tratados. É toda uma outra forma de entender e explicar a experiência afetiva. A noção de "experiência afetiva" seria um contra-senso à luz de tal perspectiva, estritamente falando, a não ser que fosse tomada como uma metáfora para a coreografia de sódio, potássio e neurotransmissores e etc. no processo de regulação de um estado afetivo cabalmente neuronal. E seria em função disso que definiremos o inconsciente do afeto?

Sabemos que a perspectiva humoral (de proveniência hipocrática) chega ao século XX reformulada e recriada a partir da biologia molecular. A possibilidade de equacionar estados psíquicos (patológicos ou não) por meio da bioquímica com certeza elimina a espessura semântica que os termos paixão e afeto possuíam até o século XIX, mesmo quando a psicofisiologia já avança na direção das neurociências. No entanto, existem autores como um Jean-Didier Vincent que, mesmo operando com os avatares da orientação da ciência dura nestes campos, conseguem manter uma tensão na articulação do saber da neurofisiologia e dos processos eletrobioquímicos com a questão do sentido, da presença afetada do 


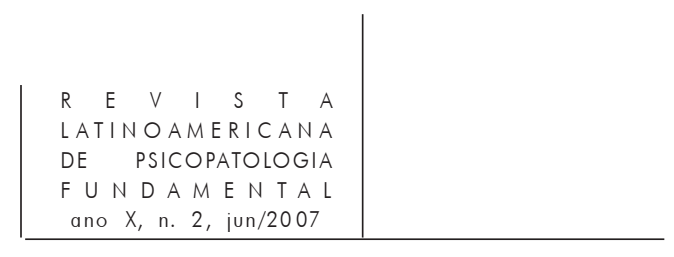

ser no mundo. Embora sem seguir uma via conceitual, o neurofisiólogo chama atenção para o fato de que o contraditório nas formulações desses termos, ainda quando marcadas pela metafísica, comporta uma dimensão que não deve ser anulada, já que ela traz em si a questão do sentido - e também mais radicalmente, a arena da qual emana a prova do sentido - que a paixão e o afeto carregam, o corpo sendo determinante. Ele colhe, nos escritos de Claude Bernard, uma passagem que traduz bem a consciência desse contraditório irredutível ao plano neuronal: "Jamais se submeterão as manifestações de nossa alma às propriedades brutas dos aparelhos nervosos, como tampouco se compreenderão suaves melodias só pelas propriedades da madeira ou das cordas do violino que são necessárias para exprimi-las". ${ }^{2}$

Contudo, a noção de afeto é colocada de tal modo que ela não se distingue bem da de paixão. O que traz um problema, já que a distinção em função da idéia de "movimento" comporta uma ambigüidade (aliás, indicada na redução à emoção). Além disso, a idéia de que os afetos ou as paixões dizem respeito a um modo passivo por sua exclusiva condição, em última instância, corporal, ou ainda a de que eles poderiam ser explicados por um princípio unificador como o "amor" - o que é manter um princípio, no fundo, metafísico -, esvazia, em muito, o que justamente necessita ser concebido. O desafio, portanto, é pensar a experiência afetiva. Existiria nela tanto uma dimensão redutora quanto uma outra expansiva. De qualquer maneira, a condição sensível enraíza em algo ou na natureza tudo o que vier a ser pensado como afeto, seja no viés psicológico ou no psicopatológico, seja no da potência criativa da vida (entendendo-se por isso a plasticidade das adaptações existenciais). Sinteticamente falando, se a "química" interfere no "sentido", e se o "sentido" pode repercutir na "química", o que nunca se deve esquecer é que aí há uma dissimetria fundamental na constituição da vida humana, sob seja qual for o regime simbólico que coordene o horizonte elaborado e praticado da cultura. A questão não se reduz a um problema de palavras. Ele exige conceituação, e nisso as inércias e os cruzamentos semânticos acabam por ter, na ponta prática da clínica, encaminhamentos redutores e brutais, mesmo quando eficazes. Jamais se avalia os efeitos na cultura, por isso é necessário pensar a experiência do afeto com todo o cuidado.

\section{II}

Toda uma série de pensadores, ao longo da modernidade e seus desdobramentos críticos, acabaram por refletir sobre as condições da experiência

2. Citado por Jean-Didier Vincent, em Biologie des passions, p. 14. 


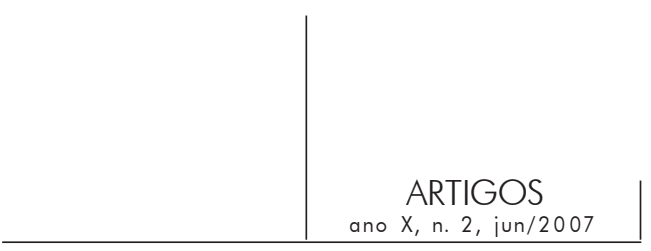

sensível e sobre o pensar modos de vida. O esforço de Kant para construir um pensamento que situasse a razão e suas condições no processo de conhecer a coisa no mais amplo aparecer acabou por ter de enfrentar a questão de como a razão é o que é inarredavelmente presa à sensiblidade e ao sentido num mundo habitado por paixões e afetos. Isso o levou a pensar uma razão arquitetônica refletida para lidar com o que não é ela, aquilo que é de outra ordem que aquela em que se posiciona a razão e seu limite. Restringindo-se a um só ponto da obra de Kant, tomemos dele a indicação em que distingue afetos e paixões no contexto da crítica da faculdade de julgar

Os afetos são especificamente distintos das paixões (Leidenschaften). Os primeiros se relacionam simplesmente ao sentimento; os segundos pertencem à faculdade de desejar e são inclinações que tornam difícil ou impossível qualquer determinabilidade do livre-arbítrio por princípios. Esses são tempestuosos e irrefletidos, aqueles, duráveis e refletidos: assim a indignação como cólera é um afeto; mas o ódio (sede de vingança) é uma paixão. Essa jamais pode e sob nenhuma relação ser dita sublime; pois, se no afeto a liberdade de espírito (Gemüt) está verdadeiramente entravada, na paixão ela está suprimida. (Kant, $1985, \S 29$, p. 1045)

Certamente que não cabe aqui, neste sobrevôo, seguir os desdobramentos do pensamento kantiano. Mas é necessário destacar que o afeto é concebido como um momento finito dentro de um processo que se abre para o ilimitado - o que está em jogo no conceito de sublime (o que nos conduziria à segunda e à terceira crítica). Ou seja, a maneira como Kant pensa o afeto o leva a colocar a experiência afetiva num plano quase paradoxal em que o sensível e o que aponta para aquilo que o excede não são descontínuos. ${ }^{3}$ Assim sendo, só a paixão perde o regime inclusivo que a concepção afetiva comportaria. De um ponto de vista conceptivo, a distinção kantiana pode ajudar a perceber as polaridades promovidas entre algo que faz parar e algo que faz expandir.

Independente da complexidade própria aos detalhes do pensar de cada um, quer seja no plano mítico, religioso, ético, político, poético, ontológico ou psicopatológico, não será difícil perceber que, com Platão, Aristóteles, os estóicos, Santo Agostinho, Pascal, Espinosa, Kant, o idealismo alemão, Kierkegaard, Nietzsche e Heidegger (só para mencionar alguns pensadores que refletiram explicitamente sobre essas questões), existe uma conceituação inclusiva do que cada pensamento articula em relação ao que afeta e à problemática de sua expressão.

3. Para uma interpretação do caráter inclusivo da razão em Kant, ver Marty, François. Raison pure, raison affectée. 


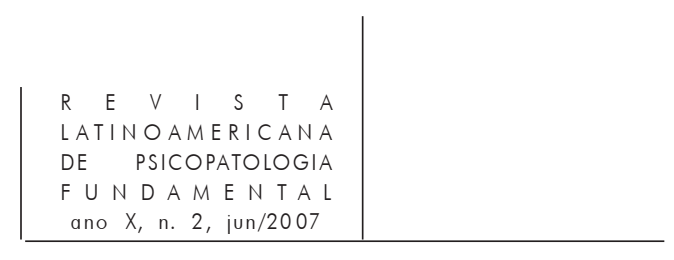

O que queremos sublinhar é que a revolução kantiana possibilitou uma releitura das formas de pensar o afeto e a paixão criando uma distribuição conceitual (na sua língua arquitetônica) que ilumina pensamentos anteriores e posteriores, mostrando que experiência afetiva é necessariamente mais espessa do que a experiência passional - não importando as palavras que utilizemos para designá-las -, uma vez que a experiência que chamamos de afetiva traz em si um processo de elaboração a partir de uma tensão entre corpo, linguagem, valor e o que afeta. Mesmo existindo uma báscula ética que pende para a experiência afetiva, a operação kantiana quebrou a simetria desses termos; de alguma forma deu uma nova dignidade ao afeto ao trazê-lo para o contexto da análise do sublime. De Kant a Freud, um conjunto significativo de pensadores trouxe o afeto enquanto centro de preocupação entre ética e estética. O conhecimento dessa tradição é importante para demarcar-se qual foi a efetiva contribuição de Freud na conceituação do afeto.

Uma outra perspectiva do problema, envolvendo agora o próprio modo de viver o afeto, poderia ser rapidamente lembrada através de uma colocação como esta de Nietzsche:

Esta secreta violação de si mesmo, esta crueldade de artista, este prazer de dar-se a si mesmo uma forma como seria feito com uma matéria difícil, recalcitrante, sofredora por marcar-se pelo ferro de uma vontade, de uma crítica, de uma contradição, de um desprezo, de um não, este trabalho inquietante e apavorantemente voluptuoso de uma alma voluntariamente em desacordo consigo própria, que se faz sofrer por prazer de fazer-se sofrer, toda esta "má consciência" ativa, verdadeira matriz de fenômenos ideais e imaginários, acabou por produzir em pleno dia uma profusão de afirmações e de belezas novas e estranhas e talvez, pela primeira vez, a beleza ela mesma. (Nietzsche, 1887, §18)

O que essa colocação obriga é ter de se levar em mente o afeto no interior da experiência com poder de realização. Muitas vezes temos de lidar com conceituações sem que os termos apareçam de modo explícito como é o caso nessa passagem. De uma maneira profunda, é o afeto articulado a uma prática do valor na experiência de criação, em função do risco de sua própria determinação. Se olharmos a clínica como um espaço de criação de sentido para vida será difícil contornar esse pensador.

Contudo, possivelmente tenha sido a fenomenologia na evolução do pensar de Husserl que mais tenha trabalhado tudo o que estaria implicado na experiência do afeto em sua constituição e a inarredável ampliação de horizonte próprio à intencionalidade e à dimensão do originário como condição da experiência, em sua maior genericidade possível, independente do controle dos valores prévios da tradição cultural e seu regime de representações. 


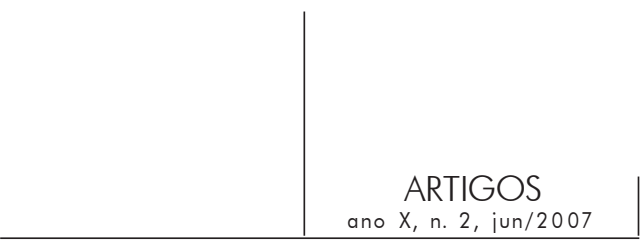

A fenomenologia, em sua plena força, trouxe algo de decisivo para se começar a pensar o afeto, a experiência afetiva, "o pulsional" e "o inconsciente", de uma maneira que mereceria especial atenção por parte daqueles que enfrentam, clinicamente, situações difíceis. Cito uma passagem do belo livro de Anne Montavont na qual o leitor poderá ter uma pequena referência dos momentos avançados do trabalho de Husserl:

O objeto me afeta, isto é, me convida a passar do implícito ao explícito; a passagem do sentido obscurecido a seu esclarecimento é justamente definido como despertar afetivo: "Que pode bem significar outro despertar que tornar o implícito de novo explícito?” (Analysen zur passiven Synthesis)]. Há bem em nossa relação ao mundo, e isso de maneira essencial, uma dimensão afetiva: os objetos exigem de nós que nos voltemos para eles a fim de lhes dar um sentido de algum modo já. O mundo pré-dado fez nascer em nós uma tendência a ser afetado que nos convida em contrapartida a constituir esse mesmo mundo, isto é, a dá-lo a nós. O fenômeno da afecção fazendo surgir o ato de um plano de fundo implícito de motivação, fazendo do agir um "re-agir" à estimulação de um pré-dado, uma resposta à sua provocação, a questão que se coloca é a de saber, enquanto instância que responde, está sempre em condição de assegurar ao sentido seu fundamento último. A relação do eu e do não-eu é com efeito uma relação assimétrica já que a iniciativa parte do não-eu: a afecção precede a ação receptiva do eu que não é nem ato puro, nem pura passividade, mas uma "um escuta e um olhar que respondem" (antwortendes Hinhören, Hinsehen). Porque afetado, isto é, no mundo e portanto no exterior de si próprio, o sujeito deve acolher-se, receber-se a si próprio se ele quer tornar-se ele mesmo. Esta "recepção ativa" é finalmente um voltar-se para um mundo que, ele, já está voltado para o sujeito, precedendo assim sua própria revelação. O "ser-afetado-por" revela, pois, ao sujeito que antes de opor-se ao mundo numa representação objetivante, ele participa do mundo, ele sempre já faz parte dele. (Montavont, 1999, p. 224-5)

Sem poder aqui me estender mais, e mesmo deixando de mencionar as contribuições importantes de Heidegger e de Deleuze sobre a questão, coloco que seria urgente uma reavaliação dessas balizas, sob pena de naturalizarmos o afeto ou simplesmente nos referirmos a ele de uma maneira consensual e ideológica, com as consequiências redutoras para uma clínica que respeite os avatares efetivos do que o humano presentifica no sofrimento paralisante ou na sua força criativa.

\section{III}

Tudo isso antecede, é concomitante a, atravessa muitas das construções psicopatológicas oriundas do discurso da psiquiatria anterior ao regime dos 


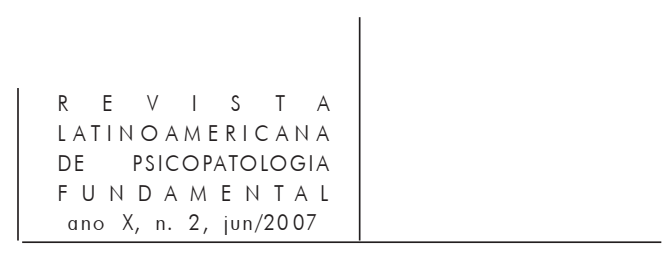

psicotrópicos. Mas em que isso nos interessa? Isso nos interessa na medida em que todo esse aluvião semântico referente ao afeto não foi ainda marcado, de maneira profunda e consistente, pela elaboração psicanalítica. Refiro-me aqui ao fato exemplar de que a psicanálise foi capaz de nos levar a poder distinguir, mesmo recorrendo a termo já usado, um fenômeno singular e uma conceituação à altura. Assim, um bom exemplo disso poderia ser o que ocorreu com a constituição do conceito freudiano de fetichismo a partir da sua última versão, quando pensa a dimensão incorporal do fetiche colocada pelo "brilho no nariz" de determinado paciente.

Se formos estudar o fetichismo veremos que a psicanálise marca o termo na cultura, além do que a análise do fetichismo da mercadoria em Marx já o havia feito. Nada de semelhante com o que acontece no uso psicanalítico do termo "afeto" - e aí talvez devamos reconhecer que a carga conceptiva do termo é maior no legado cultural formador que antecede à psicanálise (o termo fetichicismo começa a ser levado em conta desde o século XVIII). Assim, diferentemente do que aconteceu com o termo fetichismo depois da contribuição psicanalítica, o termo afeto envolve algo que ainda não foi trabalhado suficientemente, de tal forma que há muita confusão de línguas. Não conquistou nada equivalente ao conquistado com a concepção metapsicológica original do fetichismo na última concepção freudiana. ${ }^{4}$ O deslocamento da Verleunung vai do corporal (o fetichismo de 1905,

4. De acordo com Paul-Laurent Assoun, seriam três os momentos de depuração do conceito freudiano de fetichismo: a) o fetichismo é entidade clínica no campo das perversões; b) o fetichismo designa "uma certa posição do sujeito perverso diante da "castração"”; c) o fetichismo como "pensamento de uma clivagem do eu". Seu livro, bastante útil para uma visão de conjunto desse tema, permite ver que essa terceira concepção dá exemplo de uma conceituação propriamente psicanalítica em sua plena força. O seu valor metapsicológico, inconfundível se levarmos em conta uma coerência clínico-teórica especificamente psicanalítica, é muito determinado. Freud traz um modo de pensar que, neste caso, equaciona cena imaginária, acontecimento invasivo na cena, afetação, percepção, medo, terror, pânico, Verleugnung, fazer como se não existisse e derivar através de uma fixação objetal que ao mesmo tempo apague o visto e metamorfoseie num substituto que monumentalize como uma espécie de "parada-naimagem" a memória insuportável ("castração", "real"...), inconsciente, modulado por um "façamos como se ela não o fosse". Quando Freud se vê diante do "brilho no nariz" - um fetiche incorporal - numa ocorrência clínica, quando o conceitua como um fetiche (uma coisa que é dita pelo fetichista e não é visível para os outros), está produzindo um conceito que situa um fenômeno geral da divisão subjetiva e o equacionamento da clivagem do eu e o processo do fetichista em lidar com algo que seria da ordem de um traumático inaceitável para o narcisismo em formação do eu. Essa e todas as demais saídas do falante com relação ao traumático apontam para o eu e o seu silêncio, que a dimensão pulsional não apaga e carrega. Sabemos que a partir disso podemos reavaliar o sentido do objeto em Melanie Klein, Donald Woods Winnicott e 


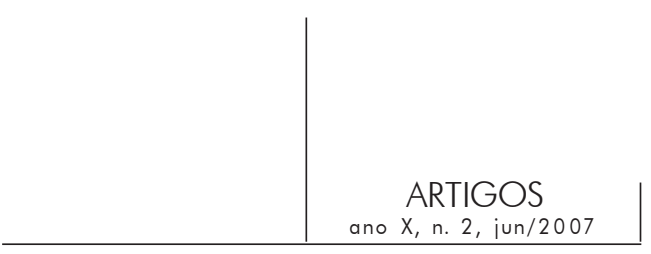

dos "Três ensaios sobre a teoria da sexualidade") a construção mais sutil, mas nem assim menos sintomática, dos fetiches não ancorados diretamente no imaginário do corpo. Fetiches atravessados pelo efeito de linguagem, assentados na metágora e não num elemento material que sustentaria a fantasia do "fetichista". O que queremos mostrar com esse exemplo da forma como um termo anterior é marcado pelo pensamento de Freud, de tal modo que se quisermos pensar o fetichismo metapsicologicamente, e não na dependência de uma sexologia sempre bastante duvidosa, estaremos diante de uma maneira de olhar inédita em três séculos. O exemplo evidencia que não há nada equivalente ao "afeto" depois da psicanálise, ou seja, a maneira psicanalítica de olhar o "afeto" não é precisa. É isso que justifica a minha insistência. O que será um conceito de afeto para psicanálise?

Portanto, o que nos detém aqui é a tarefa de criar um quadro que nos situe, diante do que já foi feito, e que venha trazer, na medida do possível, a reflexão teórica e clínica necessárias sobre a especificidade psicanalítica do conceito de afeto. Ao que nos referimos, em suma, quando se trata de falar de afeto no campo psicanalítico? Em relação ao que vem sendo estudado na literatura analítica, o que chama a atenção é a oscilação, senão a inércia, que prejudica saber o que está sendo dito quando se fala de afeto nas cogitações e concepções dos psicanalistas e daqueles que levam em consideração o saber psicanalítico em suas práticas na saúde pública. Não se trata de um exagero. Debruçar-se sobre a significação do afeto nas relações precoces, nas situações das famílias em curso, nas ordenações sociais, nos processos de acomodação identitária relativa ao possível de ser dentro de uma base mítica ou histórica, nas experiências radicais de criação, mostra, com evidência, um conjunto de construções que precisam ser explicadas e comparadas com o que a tradição reflexiva ocidental anterior à fenomenologia conseguiu articular, com os desdobramentos da fenomenologia husserliana, com a distinção heideggeriana entre afetividade e subjetividade, com os afetos de Deleuze e Guattari, com tantas outras contribuições, com o pensar da experiência afetiva dos psicanalistas depois de Freud. Muito antes de a psicanálise trazer, ou não, alguma contribuição sobre o que venha ser afeto para ela, não será difícil perceber, em tudo o que compõe a tradição cultural do Ocidente, a acentuada preocupação em definir o afeto. Isto pode ser verificado numa diversidade de textos, nos escritos no Ocidente, mas também nos escritos das

Jacques Lacan, tudo isso precisa ser trabalhado em outro momento. Aqui, a menção seria no intuito de situar a dificuldade de se conceber o conceito de afeto em psicanálise que seja levado em consideração no interior do que clivagem do eu e fetichismo equacionam de modo tão singular. 


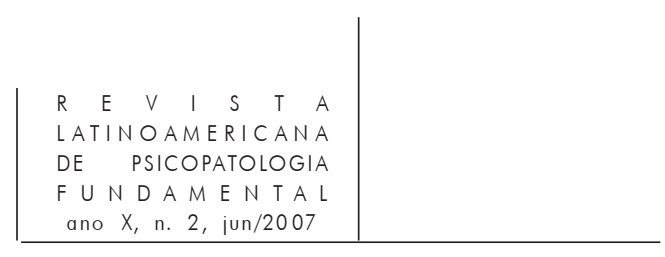

tradições pensantes das culturas do Oriente, embora sem termos as mesmas palavras para nos orientar.

Seja lá qual for a maneira, portanto, como venha se abordar o afeto, o corpo está necessariamente implicado, nem que seja um corpo junto com suas extensões tecnológicas, sejam protéticas ou não. Esse é o ponto essencial: até onde vai o corpo para o ser falante vivendo relações sociais mediadas pela pragmática dos valores que dá a cada cultura o seu suporte e horizonte históricos. Todo bebê, em qualquer parte do planeta, seja lá até onde se tenham signos dessa inserção, é recebido num mundo previamente constituído. Esse mundo o alimenta, possui seu regime de cuidados no sistema das mães, dos primatas mais complexos indo até os nossos sistemas, dentro das condições atuais do que se vive como sendo uma família, ou mesmo qualquer agrupamento vinculado que sirva, de modo forte ou fraco, de referência de natureza familiar. Nada melhor para entender isso do que se lembrar do nascimento do personagem do filme $\mathrm{O}$ show de Truman, de Peter Weir. Ali se pôde ver esse processo sendo tomado como uma verdadeira mercadoria.

A sensibilidade clínica requer toda uma atenção com a maneira como concebemos o afeto. Se lidamos com dificuldades na administração do corpo, nos processos de crescimento (toda a vida cerebral em complexificação contínua em vários planos), na formação do eu dentro de uma família ou suas contrafações, (no espaço social e suas patologias, na cultura e seus impasses), o grande cuidado é não reduzir o cuidado a um entendimento que naturalize o que está em jogo nos processos de vida em sua concreta e enorme variação. O bebê, a criança, a menina, o menino, o adolescente, um conjunto de devires que foram vividos e continuam sendo de um jeito mais ou menos adequados. A sensibilidade clínica de todos os profissionais que lidam com os desafios das soluções de problemas para aqueles que, por qualquer motivo que seja, estejam aí atrapalhados, impedidos, ou mesmo sem saída, passa por ser uma prática orientada em função de uma tradição de cuidados do gênero humano com toda a certeza, mas isso não deveria fazer esquecer que o afeto contém algo que ultrapassa a regularidade do regime biocultural do cuidado.

Se conseguirmos aceitar plenamente que o corpo vai até onde forem suas próteses, ${ }^{5}$ e também que o corpo opera afeto em todas as suas extensões, não será difícil aceitar que a experiência afetiva estará presente em todas as metamorfoses que as tecnologias provocarem nas vidas humanas (mesmo que esse corpo se

5. Para se ter uma idéia sobre todo um conjunto de práticas cotidianas ligadas às transformações protéticas dos corpos, novas formas de sentir e de viver, a leitura do livro Escape Velocity, de Mark Dery pode revelar-se útil a esse respeito. 


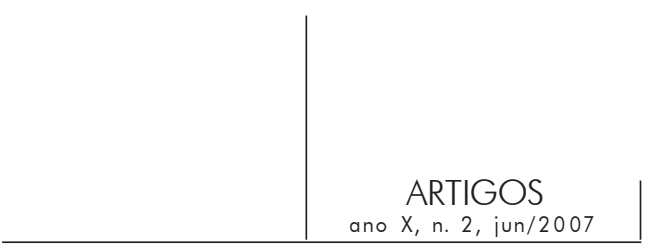

transforme a tal ponto que se coloque como outro do humano). Um híbrido continuaria sendo um corpo se tivesse de processar o seu dentro e o seu fora. Ele sempre terá um regime de lidar com no mínimo sinais de fora, do outro que si próprio. Será sua dimensão estética. Seja lá em que nível se deseje conceituar o afeto, seja ele qual for, existe um atributo implicado necessariamente em tudo o que se disser do afeto: todo afeto é estético, opera com sensações, explicitadas ou não, acessíveis ou não, que fazem o corpo trabalhar.

Todo afeto sendo estético significa que o ser afetado coloca efetivamente uma posição cindida e inclusiva. Quebra, dobra, inclui, exprime ou não. Que se pesquise da redução química à produção do sentido, o afeto envolverá sensação e algum sentido, nem que se fique reduzido à dimensão não significante ou a um campo que exige de quem sente ter de lidar com o socius, seja lá de que processo social histórico for. $\mathrm{O}$ afeto inclui necessariamente sensação, sentido e imanência.

As indicações desenvolvidas aqui, na tentativa de abordar como o afeto teria um estatuto conceitual coerente para a psicanálise, estão dirigidas a todos que se ocupam de tratar situações dificultosas, muitas vezes indo além do dificultoso, ou mesmo indo também à dimensão do impossibilitado. Assim podemos dizer que a experiência afetiva precisa ser bem discernida em qualquer forma de tratamento, seja lá com a gama dos protéticos (para falar bem sinteticamente), seja com a dos impossibilitados (os retardos, os autistas devem ser incluídos na gama desse grupo).

Elas procuram traçar um quadro que permita a quem trabalhe com tais casos refletir sobre a dimensão do afeto, no problema em si e no próprio tratamento, que, em cada caso tratado, encontra o seu lugar. Procurei assinalar alguns confins, sempre procurando distinguir, bem minimamente, o que poderia estar trazendo um entendimento do afeto nas sutilezas do fazer psicanálise.

Posturas brutais quanto ao afeto não ajudam precisar o que está em jogo nos cuidados e nos tratamentos. Caberia, então, colocar que a necessidade de uma concepção coerente da experiência afetiva em relação à psicanálise pode estabelecer uma percepção mais aguda do contínuo de soluções que forma o quinhão de cada um. Os dados foram lançados, eles repercutem, afetam um corpo situado num meio. Admitamos que a experiência afetiva tenha lugar nos limiares de déficits dos retardos ou nas estranhezas que não são apenas neurológicas dos autismos. Aceitemos que ela também venha encontrar-se nos híbridos existentes e nos futuros, em todas estas transformações do corpo, suas extensões maquínicas e suas interfaces. A experiência afetiva enraíza o ser no mundo, ao mesmo tempo em que o constrói. O mundo da criança marcado pelo regime da deficiência ou pelo "regime" do desvio, do anômalo, se exerce por caminhos que são elaborados através de artefatos de afeto. Embora isso possa parecer óbvio, o que quero destacar é que a experiência afetiva abrange esses como que

245




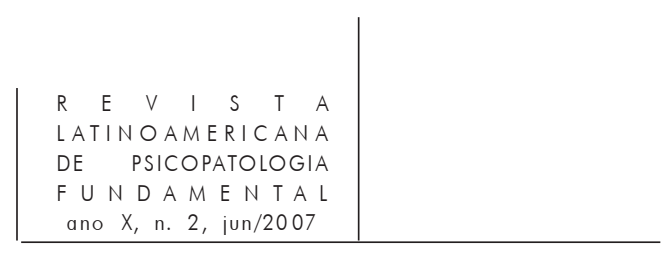

extremos, sublinhando bem que a experiência afetiva pode estar se dando tanto no deficitário, no alheado, quanto na extensão híbrida ou nos processos mais radicais de invenção.

Sendo assim, poderíamos considerar que existiriam quatro cenários que ajudam a situar os afetos no pensar psicanalítico. Quatro maneiras de situar onde e em que o "afeto" teria lugar na psicanálise. Se as tomarmos pelo que são, a saber: como quatro modalidades dimensionando a experiência afetiva em jogo no seu espaço teórico e clínico, será possível manejar tal orientação para a observação, para o estudo, para a terapêutica, para a clínica psicanalítica dos casos, em toda a sua gradação de dificuldades que põem desafios a seus práticos. O regime das equações mais primárias da criança se entendendo e interagindo na chamada da socialização passa necessariamente por alguma sucessão de desfiladeiros - tipo "corredor polonês" ou remanso - do sentir e do operar com o sentir e o seu sentido. O momento, a meu ver, pede observação e discernimento. Não se trata de supor que saibamos as respostas para colocar preto no branco o que é afeto para psicanálise. Há muito se repete que não se tem uma teoria psicanalítica do afeto. É possível que daqui a umas duas décadas ainda estaremos repetindo.

No entanto, algumas coisas foram feitas. Tem-se, ainda assim, um pequeno conjunto que faz sentido e tem relativa coerência quanto ao que se define como uma categoria conceitual pertinente para a metapsicologia na orientação das práticas. Apresento esses cenários o mais despojadamente, focando o essencial quanto à experiência afetiva em jogo no problema - aquilo em torno do que não seria um despropósito falar-se de afeto numa direção psicanalítica consistente, em algum grau. Os quatro cenários podem ser identificados num conjunto delimitado de autores da literatura psicanalítica que se ocuparam do assunto. ${ }^{6}$ A distribuição de ênfase em cada cena procura apresentar a variação dos modos da experiência afetiva em função dos planos que são necessários de serem admitidos pelos psicanalistas. Mas, em cada modo, um afeto é sofrido - o caráter passivo do ser afetado. Em cada um dos quatro, o importante é a referência que amarraria o centro da experiência afetiva, em cada um dos planos considerados.

Cabe ainda uma outra observação. O pulsional e o afetivo colocam experiências e significações. A clínica psicanalítica lida com afetos, com pulsões,

6. Nesse sentido, a leitura do livro de Ruth Stein oferece uma boa medida dos esforços empreendidos por parte dos analistas até o início dos anos 1990. 


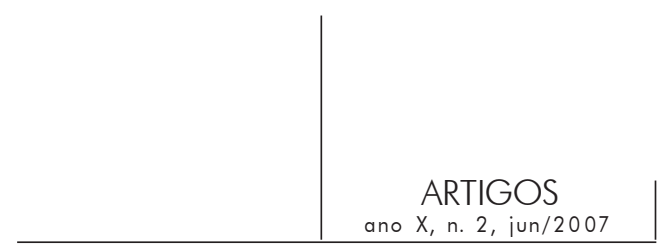

com mistos significantes. No campo das pulsões, lidamos com um espectro de impulsos que vão de regularidades a enigmas de intensidade, com seu amplo modo de expressão. O pulsional, a sexualidade infantil, suas possibilidades, seus efeitos, a identidade sexual, as identificações, os sexos, as buscas de satisfação gozosa, os artefatos, tudo isso pode estar sendo compartilhado como experiência afetiva ou não. O quanto de tudo isso terá motivação inconsciente? Será que existe mesmo essa polaridade? Não se trata de uma variação da dualidade corpo e alma. Estamos diante de uma diferença de modos que são marcados por uma motivação inconsciente, ao menos em tese. Podemos nos perguntar se não há uma determinação pulsional inconsciente que pede ser decifrada e uma determinação afetiva inconsciente que pede ser desdobrada. O caráter experiencial do pulsional e do afetivo é indiscutível, ambos, interativos, objeto e sujeito do objeto, e o uso. A diferença é que, num caso, o das pulsões, por sua própria natureza, o pulsional pode existir incorporalmente, ele inclui essa variação de modo (a boa prova disso: a terceira interpretação do fetichismo em Freud). Acredito não ser uma distinção apenas formal dizer que a experiência afetiva jamais poderia existir sem convocação da expressão do corpo, seja em que nível for. $\mathrm{O}$ que não impede que a experiência afetiva se dê em função de algo incorporal. Contudo, ambas lidam com o interagir que pode defrontar-se com o não-interagível. De qualquer modo, podemos aceitar a hipótese de determinações inconscientes que explicam e as que transformam. É toda a importância do traumático. O processo transferencial da psicanálise suporta com essa atenção. Interno e externo, o afeto sempre é entre, em cada situação, é o que parece. Para a psicanálise, determinados pontos dos impasses e das dificuldades, que são devidamente apontáveis, adquirem contorno mais preciso se olhados à luz da distribuição de ênfase dos quatro cenários. Elas são excludentes. São ênfases maiores. Apresentam-se encompassadas. O que demonstra a necessidade de elementos de inclusão para que se possa encarar tais paragens teóricas.

Destaco-os, portanto, sinteticamente, apontando neles o modo de afeto dominante, isto é, a maneira como autores recorrem a algo que parecia ser necessário ser levado em conta a respeito do "afeto", da "afetividade" em suas concepções clínicas e metapsicológicas.

Há algo referente à "experiência afetiva" que envolve a relação mãe-bebê, a zona das experiências imperativas do desenvolvimento do corpo biológico no seu meio e o nascimento de algo que vai se tornando uma pessoa no seu meio. Muito fácil perceber que este cenário e sua cena contempla em si outras inúmeras cenas ao longo do caminho de vir a ser uma pessoa, dentro das limitações de cada situação. Mas ele tem o peso próprio. Toda a importância dos estudos e concepções das relações precoces. Existem corredores que são imperativos e, ao 


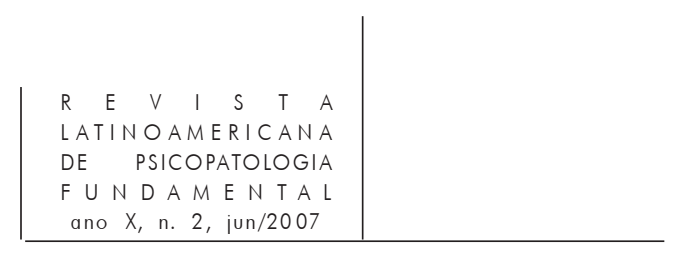

mesmo tempo, lugar de incessantes riscos. Há aí todo um conjunto de situações que fazem parte do que é preciso ser dominado para cumprir a chance de estar vivo para a alegria da evolução das espécies numa ponta e o sentimento de pertença no seio de outros múltiplos numa outra. Nisso, o marcante é o conjunto de processos pelos quais o bebê, a criança, a pessoinha em formação vão vivendo e atravessando. Uma galáxia de processos de "biologia periférica", numa feliz expressão de Boris Cyrulnik, que será determinante no jeito de ser de si, de tantos e de muitos que fazem parte do seu meio.

No interior desse império regulativo e formativo na instrumentação para aprender a viver para si e numa determinada sociedade - mesmo quando isso jamais seja pensado assim por todas as sociedades -, temos ainda como enfocar este serzinho cumprindo os ciclos do crescimento do corpo até sua autonomia motriz e todo um processo de construir a forma de ser a pessoa que terá recursos de levar a vida como alguém capaz de vivê-la e conduzi-la a termo. Impulsos e demarcações, tarefa árdua.

Há lugar aí para demarcar a especificidade do tornar-se pessoa subsumindo o império do bom senso da regulação e da manutenção das condições para que a reprodução da espécie possa acontecer, o sentido cego do imperativo vital. Contudo, certos apegos simbólicos que vão sendo preponderantes no seu curso do processo societário e cultural, forçando a inclusão de um fora família. A isso se some o valor dos processos identitários percorridos na família, na sua história com a marca ocidental, bem como seus adventos transformados a partir dos hibridismos de famílias e tribos num campo social estendido e complexo como o de nossa atualidade. Que afetos são esses contemporâneos da cena primitiva, do Édipo, da castração, para falar dogmaticamente? Como eles se transformam durante a formação de cada um? A importância desta cena é que ela se estabelece marcada por um fator de externalização, a família amplificada, a cultura, que coloca esse eu em formação como outro apropriado ou imposto num campo de valores muito instituídos ou não.

Além das cenas anteriores que acabam por semantizar a experiência afetiva e parte do que seja o seu destino, há lugar para indicar-se a cena da realização de si particularmente marcada pelo fator de externalização guiado pelo sentido do mito para determinada cultura, ou então pelo emulatório moral, religioso, político, científico, ideológico, narcísico etc. que existe no horizonte dos possíveis identitários das sociedades de temporalidade histórica. O campo da realização de si coloca o experiencial afetivo passível de se modular com figuras de alteridade construídas com ordenações ligadas ao mundo dos valores. Há toda uma gesta de heróis da cultura, que marcaram profundamente o imaginário das transformações de si. Só que aí a dimensão inconsciente presente na experiência afetiva envolve a tradição trancada ou a tradição de arquivo - algo, ali na escolha 


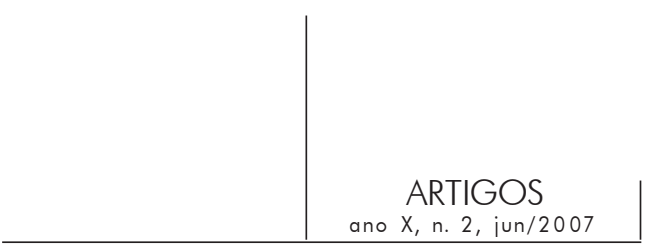

eletiva do herói, aponta para uma experiência afetiva que não está amarrada ao inconsciente do recalque. Isso não é uma questão de valor, mas sim de distinção de modos. Trata-se do caráter incorporal do herói, da heroicidade no sistema de socialização e na prática dos valores em que consiste toda cultura. Como se os processos etológicos criassem uma fantasmagoria e uma fantasística com força de agirem por conta própria, independente da autoconsciência da vontade, do controle cognitivo e mesmo da atenção crítica.

A conformação e expansão dos imaginários se adequaram aos meios que estendem o valor de uma realização de si através do espetacular e também do virtual. A experiência afetiva é compatível com o capital. Multiplicaram-se os caminhos de realização de si. Não há nenhuma incompatibilidade entre afeto e economia, dom ou valor de troca. Novas dramáticas se tecem em função do afeto e dos valores praticados na busca de ser, de tornar-se alguma coisa. O ideal de eu se compõe de tudo o que se oferta ou se obriga numa cultura. Nesta cena, como que se responde à pergunta do que se irá ser quando crescer. Que "heróis" alimentam o desenvolvimento e a construção que cada um tem de fazer, dentro e fora das medidas culturais?

A quarta cena envolve a dimensão mito-poética. Certos objetos - sensação, coisa, pessoa, idéia etc. - apresentam um poder de afetação maior, por vezes enorme, indo ao ponto do invasivo. Sua motivação é diversa. Determinados objetos sensoriais são fontes de afetação capazes de transformar o modo de estar e de lidar - colocando as idéias de um modo bem rápido - com o processo de individuação por que cada um passa desde o nascimento. Quantas etapas, quantos cruzamentos, em suma, quantas micro-experiências não foram descritas presentes efetivamente nesse processo de individuação? Há uma longa literatura psicanalítica a respeito. Por isso talvez precisemos considerar como uma cena distinguível e em jogo no processo de firmar-se como pessoa na vida de um jeito autônomo. $\mathrm{O}$ que se pode exigir de mais? Existe um tempo nos equacionamentos primários em que eu, solidão e palavra podem ser colhidos por um esbarro que provoca uma transformação afetiva no modo de ser.

A linguagem e seus silêncios funcionam como coisas e acontecimentos com força para provocar uma transformação na vida de uma pessoa até onde forem os poderes do seu mundo afetado. Todo exemplo é a rigor suspeito. Mas isso pode ocorrer tanto de forma cripta, quanto encenado na dramática dos cotidianos sociais. Tanto nas situações mais precárias, quanto, em outro extremo, naquelas que se tornam expansivas e vivas no limite. A dimensão mito-poética se mostra necessária como fonte de uma experiência afetiva para a qual valha ser pensada à luz da hipótese de um inconsciente também. Que "textos", que "cacos de textos" - concretos ou metafóricos - nos trabalharam, ainda nos trabalham? Quais aqueles que ignorados assumem um lugar importante? Quais os "textos" que 


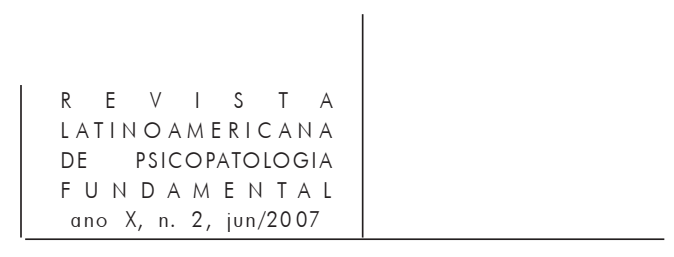

trabalharam o processo de ser alguém para si? O que a dimensão mito-poética designa se for pensada como objeto anódino - como se objeto transicional fosse - para a estruturação de uma subjetividade? O efeito de um intercessor instituído pelo mito, pelo exemplo, pela poética, pela mestria, seja lá por qual meio for - esse processo é genérico -, indica que a experiência afetiva pode ser inteiramente determinada por um pedaço eletivo de linguagem.

Assim considerada, a linguagem é um outro que me afeta plenamente. De um modo ou de outro, ela está inserida nas demais cenas que indicamos acima, embora a veemência da tônica de cada uma não coloque esse pedaço como a matéria do afetivo. Na vida de cada um sempre pode acontecer também ser tocado pelo poder da linguagem com efeitos significativos ou significantes. A forma mais simples para mostrar a especificidade da quarta cena talvez fosse remeter o leitor à alteridade potencial do que se faz e se pode fazer com a linguagem e o imaginário. Isso pode parece abstrato, mas não o é. Todo exemplo, na circunstância, é, a rigor, sempre particular, não pode vir universalizável. Cada um possui seus nacos eletivos.

Dos gaguejos aos poemas, das piadas às grandes frases, até às grandes obras, portanto da oralidade ao escrito, pode acontecer que o sentido da situação se torne marcante, senão determinante, para o corpo. O que está sendo apontado é que o concebido como sendo a experiência afetiva - no contexto em que nos movemos - por toda ordem dos cuidados até ao fazer psicanálise -, coloca a percepção de que o caráter determinante da língua na subjetivação não exclui que haja subtração ou suspensão desse mesmo poder de determinação.

A experiência afetiva diz respeito ao momento em que a palavra me falta. Isso perfura o cinturão enraizado de um outro absolutizado sob pressão comunicacional. Em outras palavras: o que se trata de destacar é que certas palavras têm peso no destino de uma pessoa.

A experiência afetiva, pensada em sua trivialidade, pode, pois, realizar-se a partir de elementos simbólicos que seriam tomados como matéria da experiência afetiva. Podemos ficar encantados com um pedaço de linguagem. É assim que consideramos útil também tomar o afeto em sua relação estrita com acontecimentos advindos por provocação do mundo imperioso da linguagem. Será que tudo que estará em jogo na vida de uma pessoa se reduz ao domínio biocultural que os estudos etológicos tão bem sabem situar? Será que as relações precoces são o nec plus ultra? Claro que não. A língua pode ser a cena em que os fenômenos afetivos estão investidos numa alteridade mais vasta e também bem mais perigosa.

Quantos personagens, quantos elementos musicais, narrativos, retóricos e imagéticos não interferiram, transformadoramente, no processo do virar uma pessoa situada? Coisas me pegaram, me pegam, mas não sei por onde, poderia se dizer. Em que lugar estou quando algo me pega e não sei em que ponto? A 


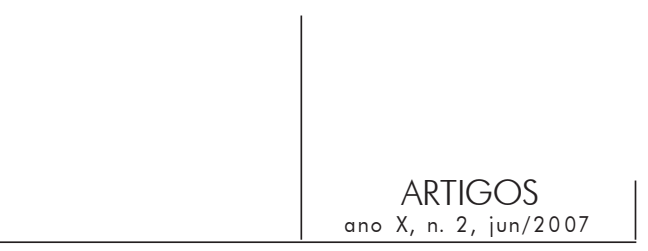

referência e a motivação inconsciente ficam enigmatizadas na experiência que se manifesta exibindo-se encarnada. $\mathrm{O}$ afeto atravessado da representação. $\mathrm{O}$ que dificulta dar-se conta da dificuldade aí neste ponto é que existe uma tendência em acreditar que a linguagem, o poder simbólico, se confunda inteiramente com a comunicação. A linguagem não é apenas interativa, ela também pode desrealizarse, ser subtrativa criando um espaço regido fora do imperativo de que tudo é social e comunicativo.

A experiência afetiva como ênfase nas cenas estaria designando sempre o caráter paradoxal: enigmar, expressar corporalmente, deixar memória do que não se sabe. Aqui, como em muitos pontos, a palavra de Donald Woods Winnicott traz a ponderação necessária para quando se lida com fenômenos sutis:

Agora é em geral reconhecido, acredito, que aquilo a que estou me referindo nesta parte de minha obra não é o tecido ou o ursinho de brinquedo, mas o uso do bebê - não tanto o objeto usado quanto o uso do objeto. Chamo atenção para o paradoxo implicado no uso pela criança daquilo que nomeei objeto transicional. Minha contribuição é a de pedir para que o paradoxo seja aceito e tolerado e respeitado, e não para que seja resolvido. Por um arroubo de funcionamento intelectual que separa as coisas é possível resolver o paradoxo, mas o preço a pagar é a perda do valor do próprio paradoxo.

Este paradoxo, uma vez aceito e tolerado, tem valor para cada indivíduo humano que não está apenas vivo e em atividade, mas que também é capaz de ser infinitamente enriquecido pela exploração do vínculo cultural com o passado e com o futuro. (Winnicott, 1982, p. xi-xii) ${ }^{7}$

O sentido desse dizer é particularmente eloqüente na formação de uma atenção que tenha de lidar com o afeto na dimensão da deficiência ou da psicopatologia, seja numa orientação psicanalítica, fenomenológica, psiquiátricofenomenológica, e, dentro das mesmas orientações, em relação a todas as manifestações que ligaríamos ao afeto na sua dimensão expansiva na vida, na cultura, no modo de viver. Talvez não precisemos de tantas cenas, talvez precisem ser ainda melhor rearrumadas para abordar a experiência afetiva dentro de

7. "It is now generally recognized, I believe, that what I am referring to in this part of my work is not the cloth or the teddy bear that the baby uses - not so much the object used as the use of the object. I am drawing attention to the paradox involved in the use by the infant of what I have called the transitional object. My contribution is to ask for a paradox to be accepted and tolerated and respected, and for it not to be resolved. By flight to split-off intellectual functioning it is possible to resolve the paradox, but the price of this is the loss of the value of the paradox itself.

This paradox, once accepted and tolerated, has value for every human individual who is not only alive and living in this world but who is also capable of being infinitely enriched by exploitation of the cultural link with the past and with the future." 


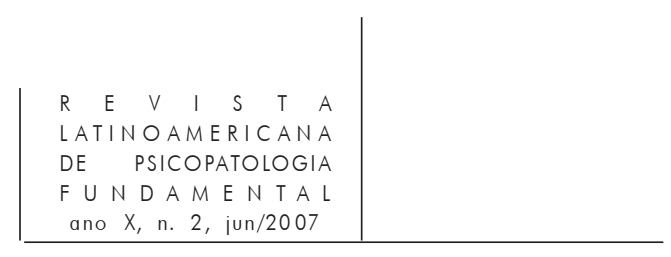

motivação inconsciente, talvez precisemos arrumar um pouco a tradição em torno dessa conceituação dificultada. Este artigo terá cumprido seu objetivo se conseguir transmitir as inquietações em função dos problemas envolvidos e algumas indicações para vir a fazer sentido o que se venha dizer na tentativa de superar essa dificuldade conceitual, senão continuaremos a repetir que não há uma teoria psicanalítica do afeto.

\section{Referências}

Aristóteles. Retórica das paixões. Trad. de Isis Borges B. da Fonseca. São Paulo: Martins Fontes, 2000.

Assoun, Paul-Laurent. Le fétichisme. Paris: PUF/Que sais-je, 1994.

Benveniste, Émile. Le vocabulaire des institutions indo-européennes. 1. Économie, parenté, société; 2. Pouvoir, droit, religion. Paris: Minuit, 1969.

Canguilhem, Georges. Le cerveau et la pensée [1980]. In: Georges Canguilhem, Philosophe, historien des sciences. Acte du Colloque (6-7-8 décembre 1990). Paris: Albin Michel, 1993.

Deleuze, Gilles e Guattari, Felix. Qu'est-ce que la philosophie? Paris: Le Editions de Minuit, 1991.

Dery, Mark. Velocidad de escape. El cibercultura en lo final del siglo XX. Madri: Ediciones Siruela, 1998.

DodDs, E. R. (1951). The greeks and the irrational. Berkeley/Los Angeles/London: University of California Press, 1997. (Em português: Os gregos e o irracional. São Paulo: Escuta, 2002).

Freud, Sigmund. Fetichismo. In: Obras Completas. Trad. de José L. Etcheverry. Buenos Aires: Amorrortu, 1998. v. XXI.

Esquema del psicoanálisis e La escisión del yo en el proceso defensivo. In: Obras Completas. Trad. de José L. Etcheverry. Buenos Aires: Amorrortu, 1998. v. XXIII.

Gaffiot, F. Dictionnaire Latin Français. Paris: Hachette, 1934.

Kant, Emmanuel. Critique de la faculté de juger. In: Oeuvres Philosophiques II. Trad. Jean-René Ladmiral, Marc B. De Launay e Jean-Marie Vaysse. Paris: Bibliothèque de la Pléiade/Gallimard, 1985.

KeHL, Maria Rita. Eu vi um Brasil na tv. In: Costa, Alcir Henrique da; Simões, Inimá Ferreira e KeHL, Maria Rita (orgs.). Um país no ar. História da tv brasileira em três canais. São Paulo: Brasiliense/Funarte, 1986. 


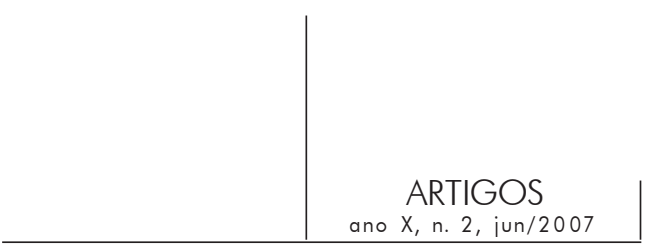

Lent, Roberto. Cem bilhões de neurônios. Conceitos fundamentais de neurociência. São Paulo: Atheneu, 2001.

Longinus. On great writing (on the sublime). Trad. de G. M. A. Grube. Indiannnapolis/ Cambridge: Hackett Publisching Company, 1991.

Marty, Pierre. Raison pure, raison affectée. Revue Épokhè, n. 2. Affectivité et pensée. Grenoble: Editions Jérôme Millon, 1991.

Montavont, Anne. De la passivité dans la phénoménologie de Husserl. Paris: PUF, 1999.

NiETzSChe, Friedrich (1887). Par-delà bien et mal/La génealogie de la morale. CEuvres Philosophiques Complètes. Trad. de Cornelius Heim, Isabelle Hildebrand e Jean Gratien. Paris: Gallimard, 1971.

Peters, F. E. Termos filosóficos gregos. Um léxico histórico. Prefácio de Miguel Baptista Pereira. Trad. de Beatriz Rodrigues Barbosa. Lisboa: Fundação Calouste Gulbenkian, 1983.

Richir, Marc. Affectivité. In: Dictionnaire de la philosophie. Encyclopadia Universalis. Paris: Albin Michel, 2000. p. 25.

Ricoeur, Paul. A l'école de la phénoménologie. Paris: Librairie Philosophique J. Vrin, 2004.

Saraiva, F. R. dos Santos. Novíssimo Dicionário Latino-Português. Rio de Janeiro/Belo Horizonte: Livraria Garnier, 2000.

StEIn, Ruth. Psychoanalytic theories of affect. London: Karnac, 1991.

Winnicott, D. W. (1982). Playing and reality. London/New York: Routledge, 1986.

Vernant, Jean Pierre (1965). Mythe et pensée chez les Grecs. Paris: François Maspero, 1981.

e Vidal-Naquet, Pierre (1981). Mito e tragédia na Grécia Antiga. São Paulo: Perspectiva, 1999.

Vincent, Jean-Didier. Biologie des passions. Paris: Odile Jacob, 1986.

\section{Resumos}

Presentación de un conjunto de formulaciones relativas al "afecto" anteriores al surgimiento del psicoanálisis. Dificultad del psicoanálisis en construir una concepción propiamente psicoanalítica. Contribución de la fenomenología de Husserl al estudio del afecto. Actualidad de las concepciones de afecto señaladas por la neurociencia. 


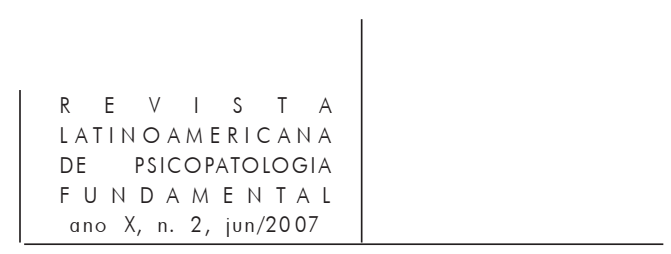

Las principales formas de considerar el problema de la concepción del afecto en el pensamiento psicoanalítico.

Palabras claves: Afecto, psicopatología, fenomenología, concepto psicoanalítico del afecto

Présentation d'un ensemble de formulations de "l'affect", antérieures à la naissance de la psychanalyse. Difficulté de la psychanalyse de construire une conception psychanalytique proprement dite. Contribution de la phénoménologie de Husserl à l'étude de l'affect. Actualité des conceptions de l'affect marquées par les neurosciences. Les façons principales de voir le problème de la conceptualisation de l'affect dans la pensée psychanalytique.

Mots clés: Affect, psychopathologie, phénoménologie, conception psychanalytique de l'affect

Here the author presents a set of statements concerning "affect" prior to the rise of psychoanalysis. Difficulties faced by psychoanalysis in constructing a specifically psychoanalytical conception are discussed. Husserl's phenomenological contribution to the study of affect is also discussed, as well as current neuroscientific-oriented conceptions of affect. The main ways that affect is conceived in psychoanalytical 254 thought are also mentioned.

Key words: Affect, psychopathology, phenomenology, psychoanalytical concept of affect

Versão inicial recebida em fevereiro de 2007

Versão revisada recebida em abril de 2007 